\title{
Fluconazole as a Safe and Effective Alternative to Ketoconazole in Controlling Hypercortisolism of Recurrent Cushing's Disease: A Case Report
}

\author{
Shu Teng Chai, ${ }^{1, *}$ Amalina Haydar Ali Tajuddin, ${ }^{1}$ Norasyikin A. Wahab, ${ }^{1}$ Norlaila Mustafa, ${ }^{1}$ Norlela \\ Sukor, ${ }^{1}$ and Nor Azmi Kamaruddin ${ }^{1}$ \\ ${ }^{1}$ The Diabetes and Endocrine Unit, Department of Medicine, National University of Malaysia Medical Centre, Kuala Lumpur, Malaysia \\ "Corresponding author: Shu Teng Chai, The Diabetes and Endocrine Unit, Department of Medicine, National University of Malaysia Medical Centre, Jalan Yaacob Latif, Bandar \\ Tun Razak, 56000 Cheras, Wilayah Persekutuan Kuala Lumpur, Malaysia. Tel: +603-91455555, Fax: +603-91456640, E-mail: chaishuteng@gmail.com
}

Received 2018 January 03; Revised 2018 April 26; Accepted 2018 May 09.

\begin{abstract}
Introduction: Ketoconazole has long been the first-line medical therapy for controlling hypercortisolism secondary to either pituitary or adrenal pathology. However, it is largely unavailable in most countries. As a result, we have turned to fluconazole as a viable alternative in view of its favourable safety profile.

Case Presentation: A 50-year-old lady developed recurrent Cushing's disease after being in remission following transsphenoidal surgery (TSS) for a left pituitary microadenoma 16 years ago. The repeat MRI showed a right pituitary microadenoma $(1.7 \mathrm{~mm} \times$ $1.3 \mathrm{~mm}$ ) for which she underwent a second TSS. However, she continued to have persistent hypercortisolism despite repeated MRIs showing absence of tumour recurrence. She refused bilateral adrenalectomy and external radiotherapy. Ketoconazole was commenced at $200 \mathrm{mg}$ twice daily for disease control but this was hindered by intolerable side effects including pruritus and skin exfoliation. In the meantime, she suffered a right hypertensive basal ganglia hemorrhage. Treatment was subsequently switched to cabergoline and the dose titrated to $0.5 \mathrm{mg}$ daily. Fluconazole $400 \mathrm{mg}$ daily was later added to control the persistent disease. Her clinical and biochemical parameters improved markedly three months after the addition of fluconazole. No adverse event was reported. Her disease has remained stable for the last 15 months up until the time of the recent clinic review.

Conclusions: This case demonstrates the long-term efficacy of fluconazole in tandem with cabergoline for the control of recurrent Cushing's disease.
\end{abstract}

Keywords: Cabergoline, Ketoconazole, Fluconazole, Pituitary ACTH Hypersecretion, Pruritus, Magnetic Resonance Imaging

\section{Introduction}

Oral ketoconazole has long been used as one of the first-line agents for controlling hypercortisolism of pituitary or adrenal origin in cases where surgery is not feasible or is non-curative. However, lately, it has not been widely available due to either suspension or restriction of its use in many countries owing to the various reported serious adverse reactions.

A recent local report published in the Malaysian adverse drug reactions newsletter (MADRAC) pointed out that a total of 26 adverse drug reactions (ADRs) with 47 adverse events associated with the use of oral ketoconazole have been documented since 2001. Of all the ADR reports, $30 \%$ were related to liver toxicity, whereas the other adverse events included milder forms of liver impairment as well as dermatological complaints. No mortality was re- ported. In unison with the actions taken by other international regulatory authorities, the Malaysian drug control authority (DCA) has issued a directive in April 2014 limiting the use of oral ketoconazole to hospitals only and to specific conditions when other effective antifungal therapies are not available or cannot be tolerated (1).

Consequently, fluconazole, another azole antifungal agent, has been recruited as a viable substitute for the medical management of Cushing's syndrome owing to its favorable safety profile.

\section{Case Presentation}

A 50-year-old female achieved remission of Cushing's disease after transsphenoidal surgery (TSS) in 1995. She presented to the endocrinology clinic in 2011 with a 3-year 
history of hypertension and gradual weight gain. On examination, she was hypertensive (blood pressure, 154/97 $\mathrm{mmHg}$ ) and overweight (body mass index, $25 \mathrm{~kg} / \mathrm{m}^{2}$ ). She had moon face, thin skin, easy bruising, and purplish striae over her thighs. Other systemic examinations were unremarkable. Her early morning serum cortisol and 24h urine cortisol levels were markedly elevated at 5,547 $\mathrm{nmol} / \mathrm{L}(171$ - $536 \mathrm{nmol} / \mathrm{L})$ and $3974.4 \mathrm{nmol} / 24 \mathrm{~h}$ (88.32 $670.68 \mathrm{nmol} / 24 \mathrm{~h}$ ), respectively. These results were accompanied by increased adrenocorticotropic hormone levels [89 pg/mL (0 - $46 \mathrm{pg} / \mathrm{mL})]$. The levels of other anterior pituitary hormones were normal. Oral glucose tolerance test excluded the diagnosis of diabetes. Her bone density measurements were normal. Magnetic resonance imaging (MRI) of the pituitary showed a right pituitary microadenoma measuring $1.7 \mathrm{~mm} \times 1.3 \mathrm{~mm}$. There was no compression of the optic chiasm, and the pituitary stalk was clearly visible (Figure $1 \mathrm{~A}$ ).

A diagnosis of recurrent Cushing's disease was made, and the patient underwent a second TSS in 2012. Unfortunately, her disease persisted after the surgery. Her serum cortisol level after an overnight dexamethasone suppression test was $600 \mathrm{nmol} / \mathrm{L}$ and 24-h urine cortisol level was $902 \mathrm{nmol} / 24 \mathrm{~h}$ ( 357 - $851 \mathrm{nmol} / 24 \mathrm{~h}$ ). A repeat MRI, however, showed no tumor recurrence (Figure 1B). The patient was offered pituitary radiotherapy or bilateral adrenalectomy, but she politely refused both treatment modalities.

Ketoconazole was commenced at $200 \mathrm{mg}$ BD to control the disease. Hydrocortisone $10 \mathrm{mg}$ in the morning and $5 \mathrm{mg}$ at noon was then added as a block-and-replace regimen due to the development of hypocortisolism symptoms a month later. However, the patient developed troublesome pruritus and skin exfoliation with ketoconazole, which hindered its use, particularly when the dose was escalated to 200 mg TDS. Consequently, her disease continued unabated; at the same time, she suffered a right hypertensive basal ganglia hemorrhage in 2014 requiring right craniotomy and clot evacuation. The treatment for hypercortisolism was subsequently switched to cabergoline, which was titrated to $0.5 \mathrm{mg}$ daily. Despite this, the disease remained active. The patient's Cushingoid features persisted, and her blood pressure was still poorly controlled. Morning serum cortisol levels increased to $763 \mathrm{nmol} / \mathrm{L}$. Hence, fluconazole $400 \mathrm{mg}$ daily was later added. Her clinical and biochemical parameters markedly improved 3 months after the addition of fluconazole (Figure 2). In September 2016, hydrocortisone was added to the existing therapy as a block-and-replace regimen upon noting that the patient's 24-h urine cortisol levels were within the lownormal range ( $155 \mathrm{nmol} / 24 \mathrm{~h}$ ).

Her disease continued to remain stable for the last 15 months up until the time of the recent clinic review(Figure
2). No adverse event was reported with the use of a combination of cabergoline and fluconazole.

\subsection{Patient Consent}

Informed consent has been obtained from the patient for publication of this article and the accompanying images.

\section{Discussion}

TSS performed by a dedicated pituitary surgeon is the optimal management of Cushing's disease (2). In our patient with recurrent Cushing's disease with a potentially resectable lesion on MRI, a repeat TSS was performed. However, the disease persisted after the surgery despite no evidence of tumor recurrence on the postoperative MRI. In such cases, the choice for a second-line therapy would be radiotherapy, bilateral adrenalectomy, or medical therapy. Our patient chose the latter after a thorough explanation of the risks and benefits associated with each option by the managing team.

Ketoconazole, an imidazole fungicide, has long been used as the first-line agent for the medical management of Cushing's disease, albeit its use is off-label. It inhibits sidechain cleavage enzymes 17,20-lyase and $11 \beta$-hydroxylase, thus, reducing cortisol and adrenal androgen synthesis (3). A multicenter retrospective study involving 200 French patients with Cushing's disease who were treated with ketoconazole monotherapy showed that up to three quarter of them experienced a decrease in urinary free cortisol levels by more than half. The median final dose of ketoconazole was $600 \mathrm{mg} /$ day (4). Despite having good efficacy both as a steroidogenesis inhibitor and antifungal agent, the reported adverse reactions associated with its use have raised safety concerns. The estimated incidence rate of symptomatic ketoconazole-induced hepatotoxicity varies from as low as $0.007 \%$ (5) to as high as $0.05 \%$ (6) and $0.2 \%$ (7). Other adverse effects reported with ketoconazole use include gastrointestinal complaints (such as nausea, vomiting, abdominal pain, and anorexia), adrenal insufficiency, skin rash, pruritus, and drug-drug interactions (8).

Considering the fact that the risks of potential harm outweigh its benefits, oral ketoconazole was discontinued in Australia in December 2013 (9), Hong Kong in 2014 (10), and China in 2015 (11). Similarly, the suspension of oral ketoconazole throughout the European Union was advocated by the European medicines agency's committee on medicinal products for human use in 2013 (12). Nevertheless, a year later, the committee for orphan medicinal products concluded that Ketoconazole HRA is of significant benefit to patients affected by Cushing's syndrome, 

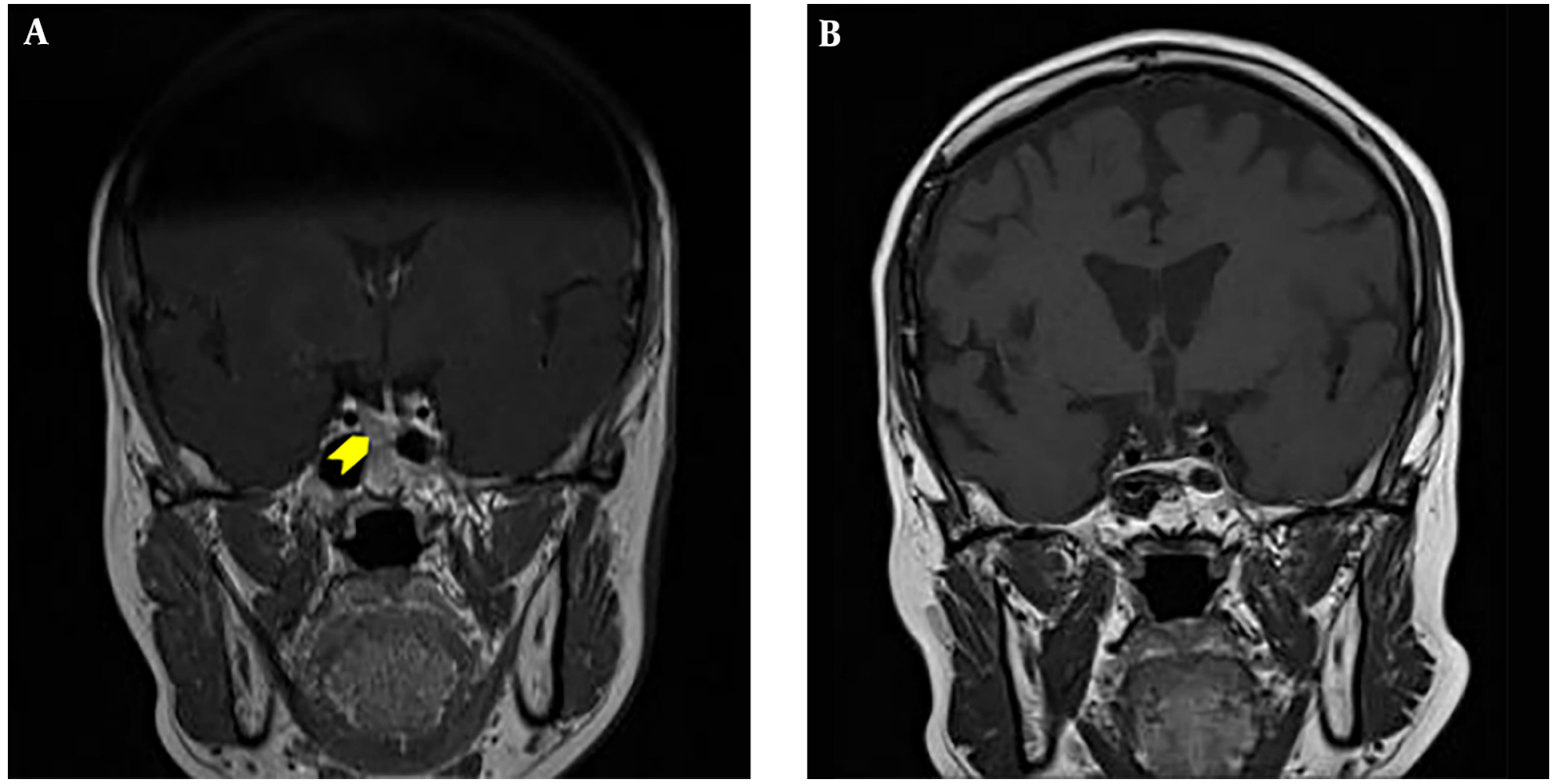

Figure 1. Pituitary MRI before (A) and five months after (B) the second TSS. A, MRI of the pituitary at presentation revealed a right pituitary microadenoma measuring 1.7 mm $\times 1.3 \mathrm{~mm}$ (yellow arrow head). B, MRI of the pituitary five months after TSS showed no evidence of tumour recurrence.

$\mathbf{a}$

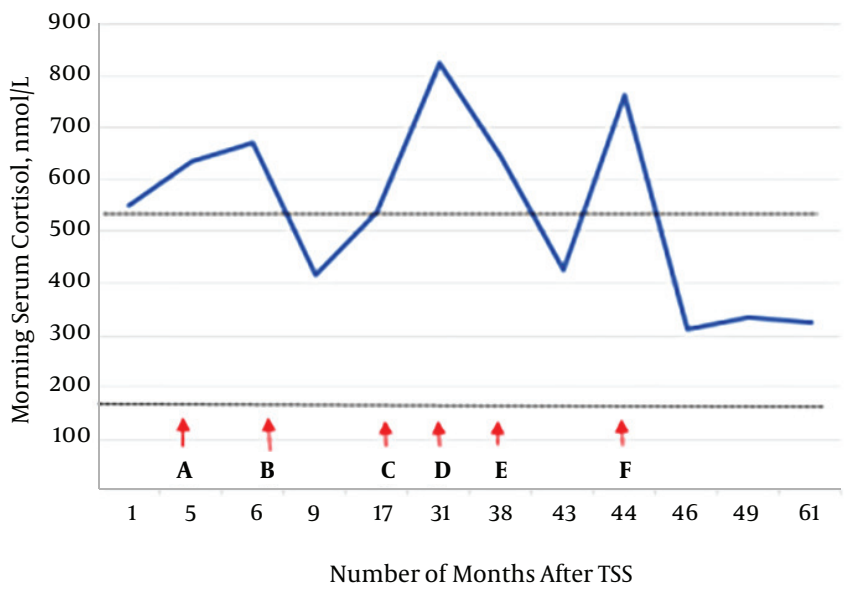

b

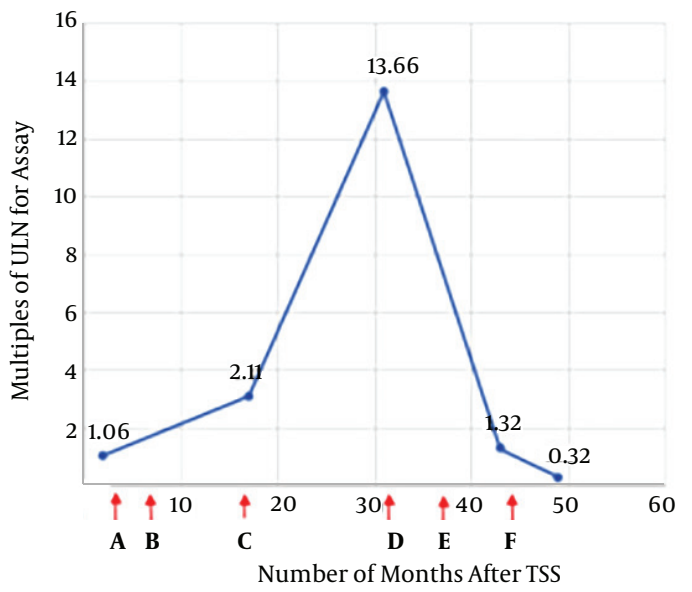

Figure 2. Serial morning serum cortisol levels (chart a) and 24-hour urine cortisol levels (chart b) following second TSS in response to the various medical therapies employed (x axes). Letters along the x-axes represent the initiation of the following agents: A, Ketoconazole $200 \mathrm{mg}$ twice daily; B, Ketoconazole $200 \mathrm{mg}$ twice daily + Hydrocortisone $10 \mathrm{mg}$ am, $5 \mathrm{mg}$ at noon; C, Ketoconazole $200 \mathrm{mg}$ thrice daily; D, Cabergoline $0.5 \mathrm{mg} 3$ times per week (Ketoconazole was withheld due to adverse effect); E, Cabergoline 0.5 mg daily (continued); F, Fluconazole $200 \mathrm{mg}$ daily and increased to $400 \mathrm{mg}$ daily after a week. Note: (i) the interval between the two dotted lines in 'chart A' represents the normal range of serum cortisol levels; (ii), twenty four-hour urine cortisol values were expressed as multiples of upper limit of normal (ULN) for the respective assays due to variable reference range of normal values from the 3 different laboratories.

and therefore, it should remain in the community register of orphan medicinal products (13). Conversely, the United States food and drug administration (U.S. FDA) cautioned healthcare professionals as well as patients about the ketoconazole-related risk of potentially life-threatening hepatotoxicity in 2013 and recommended that oral ketoconazole should only be used for endemic mycoses and when no other suitable option is available. Due to the 
inhibition of CYP3A4 enzyme by oral ketoconazole, coadministered drugs should be evaluated for possible interactions prior to prescription (14). The Malaysian DCA has echoed the actions taken by the U.S. FDA (1).

Our patient did not experience any liver toxicity, but had intolerable skin exfoliation and pruritus associated with the use of oral ketoconazole, which precluded its continued use. The presence of troublesome side effects as seen in the present case, along with a rather limited access to the oral formulation in this country, warrant the search for further alternative medications for the effective control of hypercortisolism. Fluconazole is an attractive alternative to ketoconazole as it is better tolerated and is found to be less toxic. Structurally, it has a comparatively small molecular size and lower lipophilicity. Unlike ketoconazole, which is extensively metabolized in the liver, fluconazole is cleared by the kidneys largely unconverted (15). This might explain the lower risk of hepatotoxicity associated with fluconazole use.

Riedl et al. demonstrated the efficacy and safety of fluconazole in treating Cushing syndrome secondary to an adrenocortical carcinoma over an 18-month period (16). Even with a dose escalation up to $400 \mathrm{mg}$ per day, no side effects were observed. This study also examined the in vitro effect of fluconazole on glucocorticoid production and compared it with that of ketoconazole using a rat adrenocortical cell line. Fluconazole significantly inhibited corticosterone synthesis by rat adrenocortical cells, although this effect was less potent than that of ketoconazole (16). Furthermore, in vitro effects of fluconazole on steroidogenesis were confirmed in primary cultures of human adrenocortical tissues and two adrenocortical carcinoma cell lines (17). It was observed that the inhibition exerted by fluconazole mainly involved the enzymes $11 \beta$ hydroxylase and $17 \alpha$-hydroxylase (17).

Burns et al. reported a case of prolonged in vivo efficacy of fluconazole in the medical management of Cushing's disease when used in addition to metyrapone. Metyrapone 750 mg TDS was commenced for recurrent Cushing's disease 6 months after TSS. This was followed by ketoconazole $400 \mathrm{mg}$ daily with a subsequent reduction of the metyrapone dosage. Fluconazole $200 \mathrm{mg}$ daily with a later escalation to $400 \mathrm{mg}$ daily substituted ketoconazole when it became unavailable. This combination normalized serum cortisol levels and urine cortisol:creatinine ratio for 6 months before the administration of radiotherapy (18).

Our patient remained eucortisolic for the last 15 months up until the time of the recent clinic review while on a combination regimen of fluconazole and cabergoline. No adverse event has been reported so far. This case demonstrates the efficacy of fluconazole in tandem with cabergoline for a long-term control of recurrent Cushing's disease. In agreement with the previous in vivo report (18), it supports the notion that fluconazole is a viable substitute for ketoconazole in the medical management of this rare but serious condition.

\section{Footnotes}

Authors' Contribution: Shu Teng Chai wrote the article body of the manuscript. Amalina Haydar Ali Tajuddin wrote the abstract. Norasyikin A. Wahab, Norlaila Mustafa, Norlela Sukor and Nor Azmi Kamaruddin provided consultation for the patient. Nor Azmi Kamaruddin edited the final draft of the manuscript.

Financial Disclosure: There are no financial interests in relation to the materials in the manuscript to disclose.

\section{References}

1. Malaysian Adverse Drug Reactions (MADRAC). Oral Ketoconazole: restriction of use to hospitals and tightening of indications. Malaysian Adverse Drug Reactions Newsletter; 2014.

2. Nieman LK, Biller BM, Findling JW, Murad MH, Newell-Price J, Savage MO, et al. Treatment of Cushing's Syndrome: An Endocrine Society Clinical Practice Guideline. J Clin Endocrinol Metab. 2015;100(8):280731. doi: 10.1210/jc.2015-1818. [PubMed: 26222757]. [PubMed Central: PMC4525003].

3. Nieman LK. Medical therapy of Cushing's disease. Pituitary. 2002;5(2):77-82. [PubMed:12675504].

4. Castinetti F, Guignat L, Giraud P, Muller M, Kamenicky P, Drui D, et al. Ketoconazole in Cushing's disease: is it worth a try? J Clin Endocrinol Metab. 2014;99(5):1623-30. doi:10.1210/jc.2013-3628. [PubMed: 24471573].

5. Lewis JH, Zimmerman HJ, Benson GD, Ishak KG. Hepatic injury associated with ketoconazole therapy. Analysis of 33 cases. Gastroenterology. 1984;86(3):503-13. [PubMed: 6319220].

6. Stricker BH, Blok AP, Bronkhorst FB, Van Parys GE, Desmet VJ. Ketoconazole-associated hepatic injury. A clinicopathological study of 55 cases. J Hepatol. 1986;3(3):399-406. [PubMed: 3559147].

7. Garcia Rodriguez LA, Duque A, Castellsague J, Perez-Gutthann S, Stricker BH. A cohort study on the risk of acute liver injury among users of ketoconazole and other antifungal drugs. Br J Clin Pharmacol. 1999;48(6):847-52. [PubMed: 10594489]. [PubMed Central: PMC2014312].

8. British National Formulary (BNF). Ketoconazole. National Institute of Health and Care Excellence (NICE). 2017. Available from: https://bnf. nice.org.uk/drug/ketoconazole.html.

9. Therapeutic Goods Administration (TGA). Oral ketoconazole (Nizoral) 200mg tablets. Department of Health, Australian Government; 2017. Available from: https://www.tga.gov.au/alert/oralketoconazolenizoral-200-mg-tablets.

10. Hon-Yeung C. Deregistration of Oral Pharmaceutical Products Containing Ketoconazole. Hong Kong Pharm J. 2014;21(1):6.

11. China Food and Drug Administration (CFDA). Ketoconazole. 2017. Available from: www.sfda.gov.cn/WS01/CL0087/122883.html.

12. European Medicines Agency. European Medicines Agency recommends suspension of marketing authorisations for oral ketoconazole. 2013.

13. European Medicines Agency. Recommendation for maintenance of orphan designation at the time of marketing authorization: Ketoconazole HRA (ketoconazole) for the treatment of Cushing's syndrome. 
European Medicines Agency/Committee for Orphan Medicinal Products orphan designation recommendation. 2015. Available from: www.ema.europa.eu/docs/en_GB/document_library/Orphan_ review/2015/01/WC500181644.pdf.

14. United States Food and Drug Administration (U.S. FDA). FDA drug safety communication: FDA limits usage of Nizoral (ketoconazole) oral tablets due to potentially fatal liver injury and risk of drug interactions and adrenal gland problems. 2016. Available from: http://www.fda.gov/ drugs/drugsafety/ucm362415.htm.

15. Como JA, Dismukes WE. Oral azole drugs as systemic antifungal therapy. $N$ Engl $J$ Med. 1994;330(4):263-72. doi 10.1056/NEJM199401273300407. [PubMed: 8272088].
16. Riedl M, Maier C, Zettinig G, Nowotny P, Schima W, Luger A. Long term control of hypercortisolism with fluconazole: case report and in vitro studies. Eur J Endocrinol. 2006;154(4):519-24. doi: 10.1530/eje.1.02120. [PubMed: 16556713].

17. van der Pas R, Hofland LJ, Hofland J, Taylor AE, Arlt W, Steenbergen J, et al. Fluconazole inhibits human adrenocortical steroidogenesis in vitro. J Endocrinol. 2012;215(3):403-12. doi: 10.1530/JOE-12-0310. [PubMed: 23038793].

18. Burns K, Christie-David D, Gunton JE. Fluconazole in the treatment of Cushing's disease. Endocrinol Diabetes Metab Case Rep. 2016;2016:150115. doi: 10.1530/EDM-15-0115. [PubMed: 26858837]. [PubMed Central: PMC4744941]. 